Tian Xiangshen, Zhu Longfei, Cai ZhengYu and Kong Hui*

\title{
The Relationship between MnS Precipitation and Induced Nucleation Effect of Mg-Bearing Inclusion
}

https://doi.org/10.1515/htmp-2016-0259

Received December 22, 2016; accepted August 12, 2017

\begin{abstract}
The relationship between MnS precipitation and induced nucleation effect of $\mathrm{Mg}$-bearing inclusion has been explored through scanning electron microscope and energy dispersive spectrometer (EDS). Results indicate that $\mathrm{MnS}$ prefers to precipitate on $\mathrm{Mg}$-bearing inclusions. Statistical analysis suggests that $\mathrm{MgAl}_{2} \mathrm{O}_{4}$ and $\mathrm{MgO}$ may coexist in inclusion. After etching, it is found that Mg-bearing inclusions can induce the nucleation of intragranular acicular ferrites. Based on EDS line analysis and comparison with Al-Mn-Si-O inclusion in non-Mg-treated sample, this effect can be explained by Mn-depletion zone (MDZ), which is due to the vacancy property and crystal structure of $\mathrm{MgAl}_{2} \mathrm{O}_{4}$. In the same sample, similar induced nucleation effect and MDZ are not observed around pure $\mathrm{MnS}$. This comparison implies that the formation of MDZ may be independent of MnS precipitation.
\end{abstract}

Keywords: oxide metallurgy, intragranular acicular ferrite, grain refinement

PACS $^{\circledR}$ (2010). 81.30.Mh

\section{Introduction}

In traditional opinion, inclusion is harmful to steel properties. To minimize its harmfulness, two routes have been developed. The first is to reduce its negative effect, such as amount minimization, size refinement, and

\footnotetext{
*Corresponding author: Kong Hui, School of Metallurgical Engineering, Anhui University of Technology, Maanshan, Anhui 243002, PR China; Key Laboratory of Metallurgical Emission Reduction \& Resources Recycling, Anhui University of Technology, Ministry of Education, 243002 Maanshan, PR China,

E-mail: konghui@mail.ustc.edu.cn

Tian Xiangshen: E-mail: 1660720890@qq.com, Zhu Longfei: E-mail: 1971305317@qq.com, School of Metallurgical Engineering, Anhui University of Technology, Maanshan, Anhui 243002, PR China; Key Laboratory of Metallurgical Emission Reduction \& Resources Recycling, Anhui University of Technology, Ministry of Education, 243002 Maanshan, PR China

Cai ZhengYu, School of Chemistry and Chemical Engineering, Anhui University of Technology, Maanshan, Anhui 243002, PR China, E-mail: zhengyucai_ahut@163.com
}

composition modification. The second is to utilize its positive effect to optimize the microstructure, such as inducing nucleation of intragranular acicular ferrite (IAF) during austenite-ferrite transformation. The latter is called oxide metallurgy [1], which is proposed based on Ti-bearing oxides. This technology can produce the steel with excellent Charpy impact properties and HAZ toughness.

Recently, Mg-bearing inclusion has attract much attention [2-5] and been applied in the new generation of oxide metallurgy. Compared with Ti-bearing oxides, besides inducing IAFs nucleation, $\mathrm{Mg}$-bearing inclusions can also inhibit austenitic grain growth through pinning effect. This is due to the fact that $\mathrm{Mg}$-bearing oxides are thermally stable second-phase particles [2]. However, the mechanism of its inducing effect is still under discussion.

In 2011, Song et al. [4] attributed the inducing nucleation effect to the small lattice disregistry between $\mathrm{Mg}$ bearing inclusion and $\alpha$-Fe. They first simplify the $\mathrm{Mg}$ bearing oxides as $\mathrm{MgAl}_{2} \mathrm{O}_{4}$ and $\mathrm{MgO}$, and then calculate their lattice disregistry with $\alpha$-Fe. The results are $0.6 \%$ (for $\mathrm{MgAl}_{2} \mathrm{O}_{4}$ ) and $4.03 \%$ (for $\mathrm{MgO}$ ), respectively. Bramfitt's theory [6] indicates that if lattice disregistry is less than $6 \%$, nucleation free energy barrier will be reduced, and heterogeneous nucleation will be well induced. But this explanation isn't consistent with inclusion complexity. On the one side, coexistence of $\mathrm{Mg}, \mathrm{Al}$, $\mathrm{Si}, \mathrm{Mn}$, and $\mathrm{S}$ in inclusion means that simplification of $\mathrm{MgAl}_{2} \mathrm{O}_{4}$ isn't accurate. On the other side, PCPDFWIN Database of JCPDS (version 1.1.1.0, 2002) indicates that the kinds of finely crystal structure for $\mathrm{Mg}-\mathrm{Al}-\mathrm{O}, \mathrm{Mg}-\mathrm{Al}-$ $\mathrm{Mn}-\mathrm{O}$ and $\mathrm{Mg}-\mathrm{Al}-\mathrm{Si}-\mathrm{O}$ are 62, 9, and 84, respectively. Considering the complicated environment, such as $\mathrm{Fe}$ matrix and temperature as high as $1873 \mathrm{~K}$, the exact structural parameters of Mg-bearing oxides could not be confirmed. Moreover, Yang cai fu et al. [5] have clearly pointed out that $\mathrm{MgO}$ is impotent to induce IAF nucleation. This is contrary to lattice disregistry theory.

In 2015, our group has proposed Mn-depletion zone (MDZ) theory to explain the mechanism of IAF nucleation induced by Mg-Al-O inclusions [7]. This is based on the following experimental and theoretical evidences. On experimental side, energy dispersive spectrometer (EDS) line analysis qualitatively indicates that $\mathrm{Mn}$ content shows a valley in Fe matrix around $\mathrm{Mg}-\mathrm{Al}-\mathrm{O}$ inclusion. 
The same tool has been utilized by Wang Xinhua et al. [8] and Song bo et al. [9] to qualitatively prove the existence of MDZ in Rare earth-bearing inclusion and Ti-Mg inclusion. On theoretical side, the vacancy property and crystal structure of $\mathrm{MgAl}_{2} \mathrm{O}_{4}$ are discussed to prove that it's potential to accommodate $\mathrm{Mn}$ ions [7].

However, due to inclusion complexity, more experimental evidences are needed, and more issues should be clarified. For example, about the origin of MDZ around Tibearing particles, there are still two viewpoints: (1) the $\mathrm{MDZ}$ is produced by $\mathrm{MnS}$ precipitation on the $\mathrm{Ti}_{2} \mathrm{O}_{3}$ inclusion during cooling process [10]; (2) $\mathrm{Ti}_{2} \mathrm{O}_{3}$ can absorb $\mathrm{Mn}$ atoms from the steel matrix [11]. Our previous studies also indicate that $\mathrm{MnS}$ precipitates on $\mathrm{Mg}$-bearing inclusion [7]. Thus, what is the relationship between MnS precipitation and IAFs nucleation? How Mg-bearing inclusion can absorb Mn ions through the interface of MnS? Whether MDZ is also existent around pure MnS? These issues are the aim of this article.

\section{Experimental Procedure}

The experiment is carried out in a high-heat tube-type resistance furnace (KSY-10-18) under an argon atmosphere. The commercial $20 \mathrm{MnSi}$ (about $1200 \mathrm{~g}$ ) were charged into an alumina crucible. After preheating, the charged alumina crucible was lowered into the hot zone of the resistance furnace with a graphite outer crucible. The temperature of the furnace was maintained at $1873 \mathrm{~K}$. When melting was done, appropriate amounts of Aluminum and Magnesia alloy (Mg: 8\%, mass percentage) were added into the molten steel in turn. When melting is down, crucible was held for 20 minutes, and then taken out. After solidification, sample is quenched into water. The comparison sample is prepared without Magnesia alloy addition during the same experimental procedure. The composition of both samples is shown in Table 1.

The morphology and composition of inclusions were characterized by scanning electron microscope (SEM)

Table 1: Chemical composition of steel samples (mass percentage).

\begin{tabular}{lrrrrrrr}
\hline Mass Pct & C & Si & Mn & P & S & Sol. Al & Mg \\
\hline $\begin{array}{c}\text { Mg-treated } \\
\text { sample }\end{array}$ & 0.14 & 0.25 & 1.01 & 0.018 & 0.026 & 0.0012 & 0.0020 \\
$\begin{array}{c}\text { Comparison } \\
\text { sample }\end{array}$ & 0.18 & 0.39 & 1.21 & 0.022 & 0.022 & 0.0008 & $/$ \\
\hline
\end{tabular}

(JSM-6510LV) and EDS (INCA Feature X-Max 20). Moreover, line scanning and mapping functions of EDS are utilized to reveal the elements distribution in inclusion. The sample microstructure was observed by optical microscope and SEM.

The data processing for EDS point analysis is carried out following Wang Xinhua et al. [12]. First, iron was excluded to eliminate the contribution of signals from the steel matrix. Then oxygen was ruled out due to insufficient accuracy. Finally, the content of remaining elements was normalized to $100 \%$, and reported in mole percentage.

\section{Results and discussion}

Through SEM-EDS mapping analysis, the typical Mgbearing inclusion figures are present in Figure 1. It can be seen that elements of $\mathrm{Si}, \mathrm{Mn}, \mathrm{Mg}, \mathrm{Al}$ and $\mathrm{S}$ coexist in inclusion, which means its composition complexity. Though precise analysis of inclusion is difficult, qualitative discussions are still shown below.

First, earlier report has pointed out that even $2 \mathrm{ppm}$ $\mathrm{Mg}$ addition resulted in the oxide formation change from $\mathrm{Al}_{2} \mathrm{O}_{3}$ to $\mathrm{MgAl}_{2} \mathrm{O}_{4}$ [13]. However, mole ratio $(\mathrm{Mg} / \mathrm{Al})$ of $\mathrm{Mg}$ bearing inclusion is not equal to the ideal value ( 0.5 for $\mathrm{MgAl}_{2} \mathrm{O}_{4}$ ). To precisely character this feature, each central mole ratio of $\mathrm{Mg} / \mathrm{Al}$ for over $50 \mathrm{Mg}$-bearing inclusions has been analyzed through EDS point function, and calculated as mole ratio $\left(\mathrm{MgO} / \mathrm{Al}_{2} \mathrm{O}_{3}\right)$ to more intuitive. Its distribution is shown in Figure 2. It is found that this ratio for all inclusions is larger than 2 and varies in a wide range. This suggests that for Mg-bearing inclusion, its composition isn't constant, and compared with single assumption of $\mathrm{MgAl}_{2} \mathrm{O}_{4}$, mixture between $\mathrm{MgAl}_{2} \mathrm{O}_{4}$ and $\mathrm{MgO}$ may be more reasonable. These results are consistent with our previous report [7] and hint the complexity of inclusion feature. Moreover, the relationship between mole ratio $\left(\mathrm{MgO} / \mathrm{Al}_{2} \mathrm{O}_{3}\right)$ and IAF nucleation effect induced by $\mathrm{Mg}$-bearing inclusion will be focus of our future work.

Second, EDS mapping figures of Figure 1 indicate that sulfur congregates around $\mathrm{Mg}$-bearing inclusion. It is known that due to high concentration product $\left(a_{[\mathrm{Mn}]} \times a\right.$ [S], $a$ means the activity), MnS cannot form in molten steel [14]. However, accompanying solidification process, concentration product decreases and element segregation occurs. These lead to the MnS segregation. Moreover, this segregation prefers to heterogeneously nucleate on solid substrate, which results in sulfur accumulation around inclusion. As for $\mathrm{Mn}$, due to its existence in 

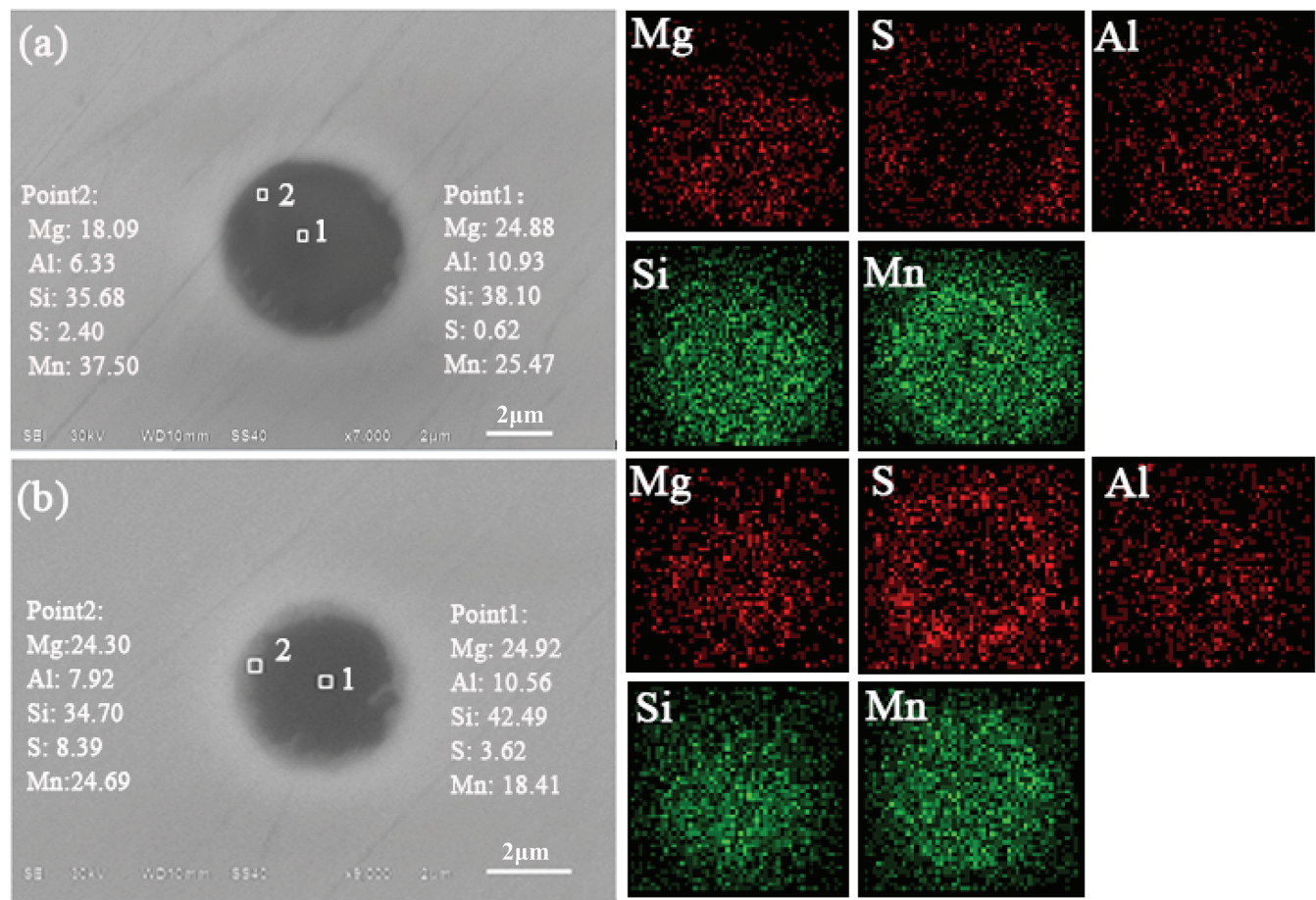

Figure 1: SEM micrographs, EDS point results, and EDS mapping images for typical Mg-bearing inclusions (a-b) in Mg-treated sample.

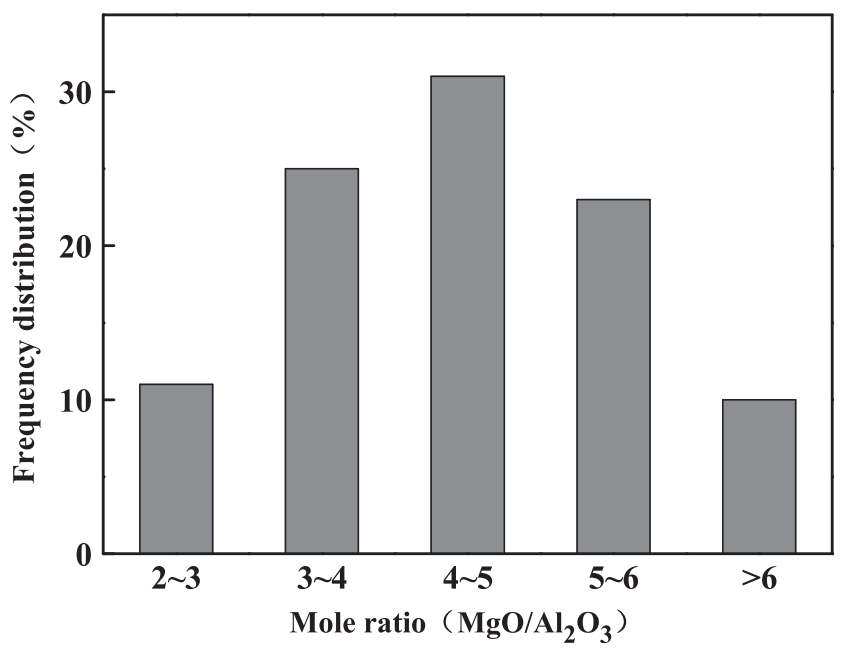

Figure 2: The distribution of central mole ratio $\left(\mathrm{MgO} / \mathrm{Al}_{2} \mathrm{O}_{3}\right)$ for $\mathrm{Mg}$ bearing inclusions.

whole inclusion, its congregation cannot be clearly observed. However, EDS point analysis still indicates that Mn content at margin is higher than it at center (shown in Figure 1). It should be mentioned in our sample, pure MnS inclusion also exists.

Third, even at the inclusion margin, elements of $\mathrm{Mg}$ and $\mathrm{Al}$ are also found. This means that MnS precipitation cannot isolate Mg-bearing inclusion from Fe matrix.
Figure 3 (a)-(b) describes the Mg-treated sample's optical microstructure after etching in $3 \mathrm{vol} \%$ Nital solution. The typical microstructure with IAFs is found, which is similar to that in Ti-treated steel $[15,16]$. Its character is that IAF plates formed independently at large angles boundaries to each other among the prior austenite grain boundaries. This structure is totally different from that of comparison sample (shown in Figure 3 (c)). The comparison sample is prepared without $\mathrm{Mg}$ alloy addition during the same experimental procedure, and its main inclusion type is Si-Mn-Al-O (shown in Figure 3 (d)). This comparison confirms the positive effect of $\mathrm{Mg}$-bearing inclusion on the grain refinement.

Figure 3 (a)-(b) also clearly indicates that these IAF plates originate from a dark spot, which was supposed as inclusion. To further explore its nature, the sample's etched microstructure was characterized by the SEM and EDS (shown in Figure 4 (a)). It can be seen that several laths emanate from a single inclusion, which confirm that Mg-bearing inclusion indeed induces the formation of IAFs. This appearance is consistent with the nature of oxide metallurgy. Then an issue should be clarified. Why nucleation of IAFs can be initiated from an inclusion?

In fact, oxide metallurgy has been proposed based on Ti-bearing inclusion, and different kinds of theory have been utilized to explain its mechanism. Among them, 

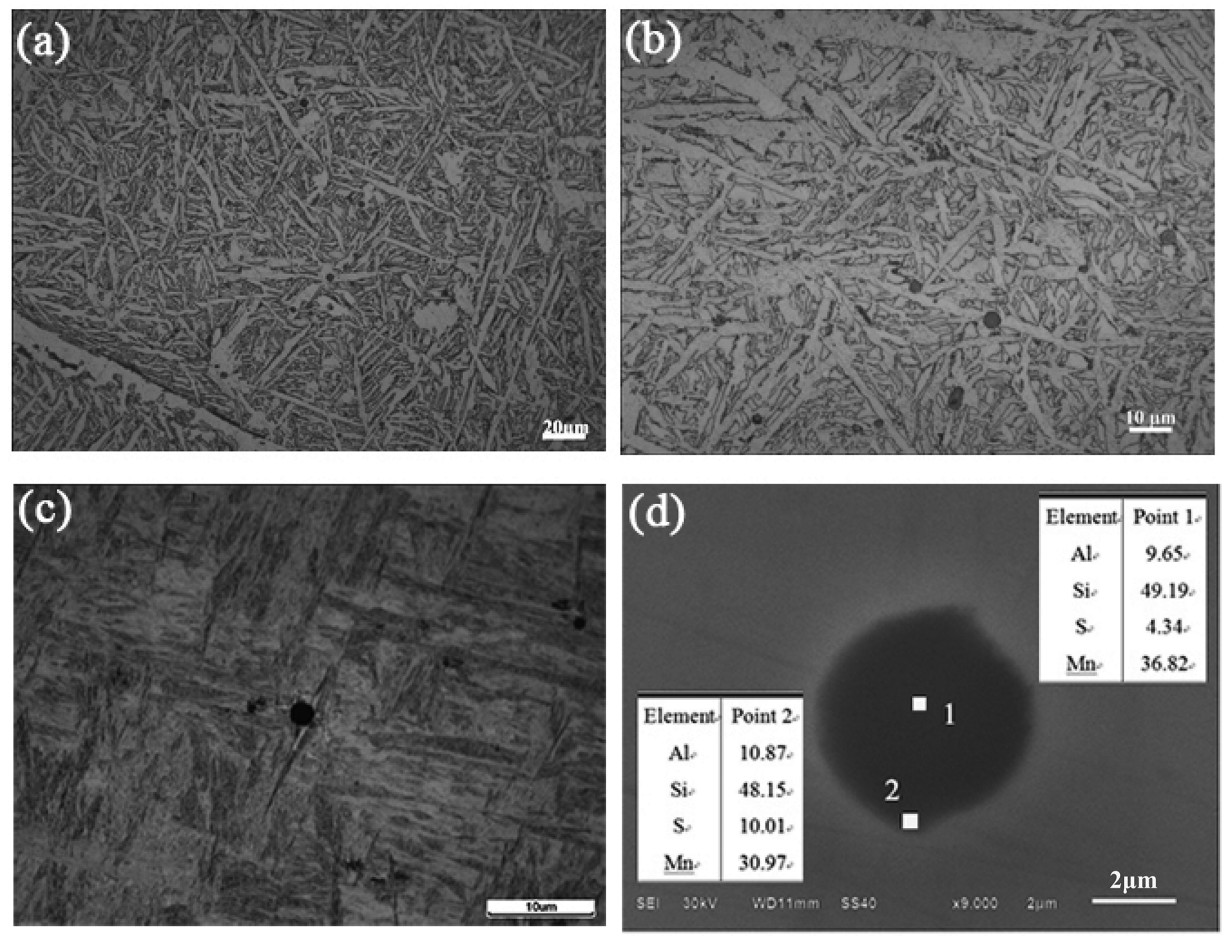

Figure 3: (a-b) The Mg-treated sample's optical microstructure, (c) The comparison sample's optical microstructure, (d) The SEM micrograph for typical Al-Si-Mn-O inclusion in comparison sample.

MDZ mechanism has been widely accepted [15-18]. The key of this mechanism is that inclusions can absorb neighboring $\mathrm{Mn}$ atoms from Fe matrix. If corresponding supplement isn't applied, this will leads to a manganesedepleted zone in Fe matrix adjacent to inclusion. Since Mn can stabilize austenite, its depletion will promote the nucleation of ferrites.

In 2015, based on solid theoretical and experimental foundation, MDZ mechanism has been proposed by our group to explain the nucleation effect of $\mathrm{Mg}$-bearing inclusion [7].

On theoretical side, three conditions have been met. First, magnesium vacancy is one of the intrinsic defects in $\mathrm{MgAl}_{2} \mathrm{O}_{4}$ through computer simulation based on empirical potential parameters [19]. Second, in ideal $\mathrm{MgAl}_{2} \mathrm{O}_{4}$, only one-eighth of tetrahedral interstices are occupied by $\mathrm{Mg}$ ions. The remaining tetrahedral interstices are empty, and potential to accommodate $\mathrm{Mn}$ ions. Third, the effective ionic radius of $\mathrm{Mg}$ (four-coordinated $\mathrm{Mg}^{2+}: 0.057 \mathrm{~nm}$ ) is similar to that of Mn (fourcoordinated $\mathrm{Mn}^{2+}: 0.066 \mathrm{~nm}$ for high-spin state) [20]. It should be mentioned that as for Mn, the value of effective ionic radius is listed according to the corresponding coordination number and valence state.
On experimental side, the absorption of Mn ions by Mg-Al-O has been proved by macroscopic and microscopic results.

From microscopic view, it can be seen that the content of Mn shows a valley in steel matrix around inclusion (Figure 4 (b)). This is totally different from the evolution of Mn content in Figure 4 (c), which is observed around Si-Mn-Al-O inclusion in comparison sample. Though the EDS line only qualitatively reflects the evolution of $\mathrm{Mn}$ content along inclusion and around steel matrix, this still hints the existence of Mn-depletion zone. In fact, the similar results are also observed in Rare earth-bearing inclusion and Ti-Mg inclusion $[8,9]$, which are used to qualitatively prove the MDZ existence.

From macroscopic view, Mn-doping on the $\mathrm{Mg}$ site in $\mathrm{MgAl}_{2} \mathrm{O}_{4}$ has been well studied, such as $\mathrm{Mg}_{0.5} \mathrm{Mn}_{0.5} \mathrm{Al}_{2} \mathrm{O}_{4}$ [21].

Based on upper two sides, a conclusion may be drawn that the absorption of $\mathrm{Mn}$ by $\mathrm{MgAl}_{2} \mathrm{O}_{4}$ is feasible and reasonable. Thus, these $\mathrm{Mg}$-bearing inclusions can also produce MDZ in steel matrix around them.

If $\mathrm{MDZ}$ phenomenon indeed originates from $\mathrm{Mg}$ bearing inclusion, and results in the IAF nucleation, two 

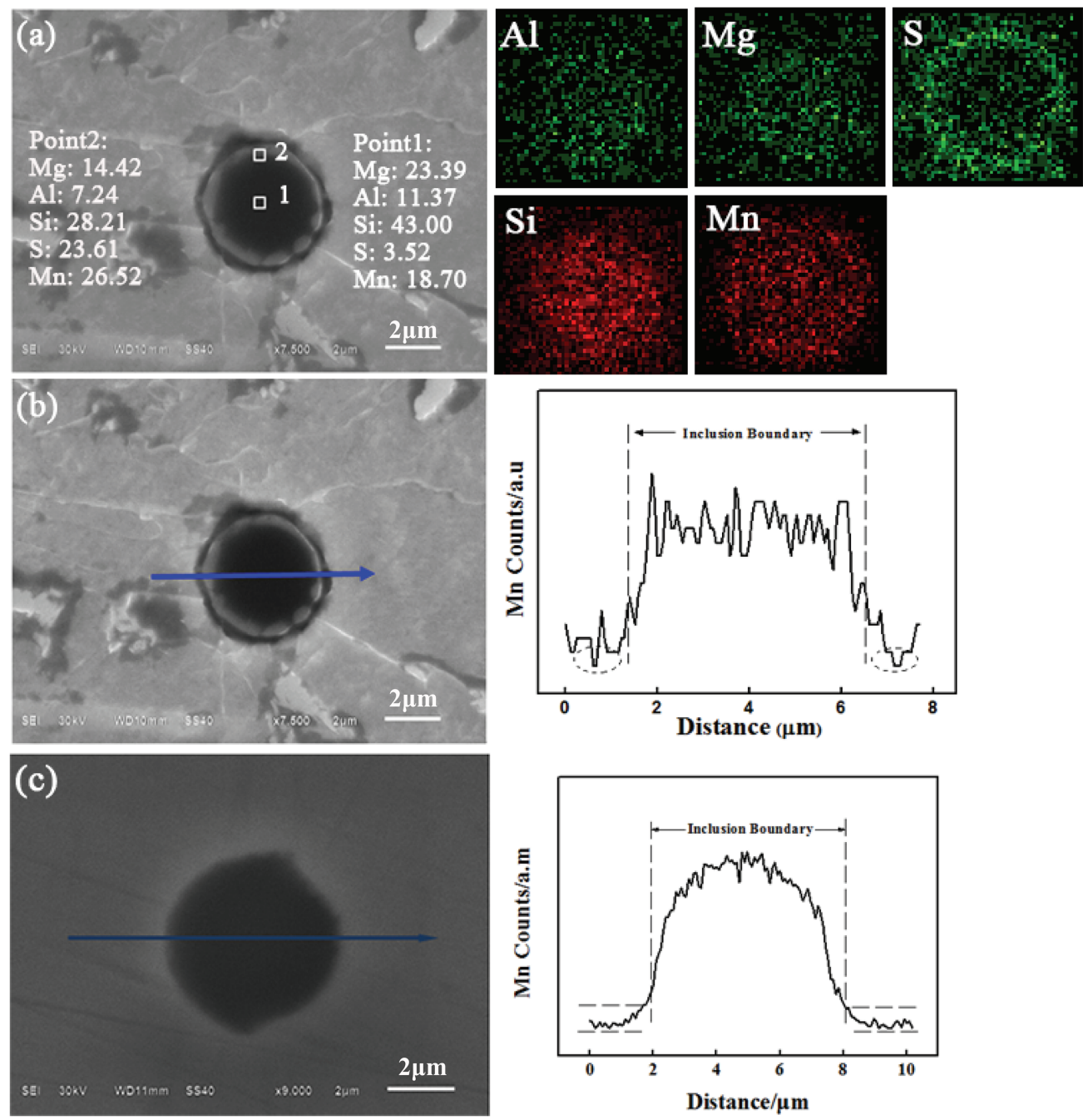

Figure 4: (a) The SEM micrograph and EDS mapping images for typical Mg-bearing inclusion in Mg-treated sample after etching, (b) EDS Line analysis of Mn along the nucleation site of Mg-bearing inclusion and surrounding steel matrix, (c) SEM micrograph, and EDS Line analysis of $\mathrm{Mn}$ along inclusion and surrounding steel matrix for typical Al-Si-Mn-O inclusion in comparison sample.

issues about MnS should be clarified. First, the Mg-bearing inclusions are surrounded by MnS, how can they absorb Mn ions from Fe matrix through MnS interface? Second, whether pure MnS inclusion can also lead to MDZ, and further induce IAFs nucleation?

For the first issue, based on the systematic analysis on inclusion (shown in Figure 1 and Figure 4), it can be seen that elements of $\mathrm{Mg}$ and $\mathrm{Al}$ are also found at the inclusion margin. Thus, Mg-bearing inclusions are not totally isolated from $\mathrm{Fe}$ matrix by $\mathrm{MnS}$ and can still lead to MDZ.

To settle the second issue, analysis on pure MnS inclusion in Mg-treated sample is carried out. From Figure 5, it can be seen that the feature of MnS in etched sample is totally different from that of Mg-bearing inclusion. First, no other elements are found in pure MnS inclusion. Second, MnS cannot induce IAFs nucleation. Third, MDZ appearance is not observed around MnS inclusion. Compared with results in Figure 4 (b), a conclusion can be drawn that MDZ is indeed originates from Mg-bearing inclusion and independent of MnS. This can be explained by the diffusion coefficient of $\mathrm{Mn}$. This value is $1 \times 10^{-8} \mathrm{~m}^{2} / \mathrm{s}$ in molten steel $(1600 \mathrm{~K})$ and $5.97 \times 10^{-13} \mathrm{~m}^{2} / \mathrm{s}$ in austenite $(1193 \mathrm{~K})$, respectively. Due to the high diffusion coefficient of Mn in molten steel, its precipitation can be compensated by nearby $\mathrm{Fe}$ matrix. Thus, MDZ phenomenon isn't observed around pure MnS. While in austenite, this value is very small, which leads to the absent of supplement. So, for $\mathrm{Mg}$ bearing inclusion, $\mathrm{MDZ}$ is formed since $\mathrm{MgAl}_{2} \mathrm{O}_{4}$ can absorb $\mathrm{Mn}$ atoms from the steel matrix during austenite stage. 

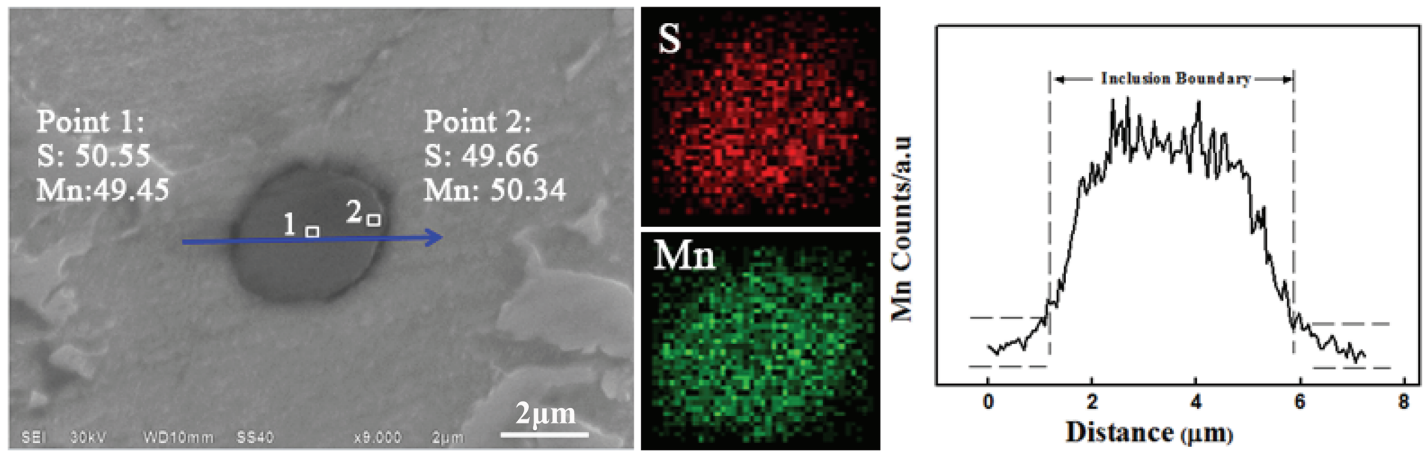

Figure 5: The SEM micrograph, EDS mapping images and EDS Line analysis of Mn for pure MnS in Mg-treated sample after etching.

\section{Conclusion}

The character of inclusion and microstructure for carbon structural steel containing Mg-bearing inclusion was studied through SEM and EDS. It is found that MnS prefers to nucleate on $\mathrm{Mg}$-bearing inclusions. However, even at inclusion margin, elements of $\mathrm{Mg}$ and $\mathrm{Al}$ are both found, which means MnS precipitation doesn't isolate Mg-bearing inclusion from Fe matrix. The statistical analysis of mole ratio $\left(\mathrm{MgO} / \mathrm{Al}_{2} \mathrm{O}_{3}\right)$ suggests that $\mathrm{Mg}$-bearing inclusion may be mixture of $\mathrm{MgAl}_{2} \mathrm{O}_{4}$ and $\mathrm{MgO}$. After etching, typical microstructure of IAFs is observed, which is due to the nucleation effect induced by Mg-bearing inclusions. MDZ theory is proposed to explain this effect and confirmed by EDS line analysis. Through comparison with pure MnS inclusion, origin of MDZ is attributed to the vacancy property and crystal structure of $\mathrm{MgAl}_{2} \mathrm{O}_{4}$.

Acknowledgments: This work was supported by the National Natural Science Foundation of China (No. 51474001, No. 51304001), Anhui Provincial Natural Science Foundation (No. 1608085J10), Talent support program for Higher Learning Institutions of Anhui Province (No. gxbjZD2016042), and Anhui University of Technology graduate innovation research (No. 2016164).

\section{References}

[1] J. Takamura and S. Mizoguchi, Proceedings of the sixth international iron and steel congress, Nagoya, 1 (1990) 591-597.

[2] A. Kojima, A. Kiyose, R. Uemori, M. Minagawa, M. Hoshino, T. Nakashima, K. Ishida and H. Yasui, Nippon Steel Tech. Rep., 90 (2004) 292-413.
[3] K. Zhu and Z.-G. Yang, J. Mater. Sci. Technol., 27 (2011) 252-256.

[4] B. Wen, B. Song, N. Pan, Q.Y. Hu and J.H. Mao, Ironmak Steelmak., 38 (2011) 577-583.

[5] C. Feng, Y. Cai-Fu, S. Hang, Z. Yong-Quan and X. Zhou, J. Iron Steel Res. Int., 16 (2009) 69-74.

[6] B.L. Bramfitt, Metall. Trans., 7 (1970) 1987-1995.

[7] K. Hui, Z. YaHui, L. Hao, X. Yunjin, L. Jie, Y. Qiang and C. Zheng Yu, Adv. Mater. Sci. Eng., 2015 (2015) 378678378683.

[8] X.X. Deng, M. Jiang and X.H. Wang, Acta Metall Sin-Engl., 25 (2012) 241-248.

[9] M.-M. Song, B. Song, C.-L. Hu, W.-B. Xin and G.-Y. Song, ISI] Int., 55 (2015) 1468-1473.

[10] K. Yamamoto, T. Hasegawa and T. Takamura, ISIJ. Int., 36 (1996) 80-86.

[11] J.H. Shim, J.S. Byun, Y.W. Cho, Y.J. Oh, J.D. Shim and D.N. Lee, Scr. Mater., 44 (2001) 49-54.

[12] X.-J. Zhuo, Y.-Q. Wang, X.-H. Wang and H.-G. Lee, J. Iron Steel Res. Int., 17 (2010) 10-16.

[13] S.-J. Luo, Y.-H. Frank Su, L. Muh-Jung and J.-C. Kuo, Mater. Charact., 82 (2013) 103-112.

[14] D. Yang, M. Jiang, S.L. Lei, X.H. Wang and W.J. Wang, J. Iron Steel Res. Int., 26 (2014) 12-15.

[15] C. Zhengyu, Z. Yahui, T. Lianhai, Y. Qiang and K. Hui, Mater. Test., 57 (2015) 649-654.

[16] J.-S. Byun, J.-H. Shim and Y.W. Cho, Scripta Mater., 48 (2003) 449-454.

[17] C.C. Zheng, X.M. Wang, S.R. Li, C.J. Shang and L.X. He, Sci. China Technol. Sc., 6 (2012) 662-671.

[18] J.-S. Byun, J.-H. Shim, Y.W. Cho and D.N. Lee, Acta Mater., 51 (2003) 1593-1606.

[19] F.-W. Zhang, Q.-R. Zhang, T.-Y. Liu, -Y.-Y. Sun, K. Tao and G. Julian, J. Univ. Shanghai Sci. Technol., 27 (2005) 104-106.

[20] R.D. Shannon, Acta Cryst. A, 32 (1976) 751-767.

[21] M.-L. Li, Theoretical Study on Properties of Magnesium Aluminates Spinel Materials, PhD Thesis, Northeastern University, China (2009), pp. 41-50. 